\title{
Comparative Evaluation of Analgesic, Anti-inflammatory and Anti- pyretic Effects of Synthetic Derivatives of Organoantimony (V) Ferocenyl Benzoate with Piroxicam
}

\author{
Muhammad Shoaib Akhtar', Zulfiqar Khan ${ }^{1}$, Muhammad Naveed Mushtaq ${ }^{1}$ \\ and Muhammad Salman Akhtar² \\ ${ }^{1}$ Faculty of Pharmacy, University of Sargodha, Sargodha, Pakistan \\ ${ }^{2}$ Division of Cardiology, Staten Island University Hospital, New York, USA
}

Received: August 27, 2015; Accepted: December 12, 2015; Published (Web): February 17, 2016

\begin{abstract}
The current study was planned to evaluate comparative anti-inflammatory, analgesic and anti-pyretic activities of two newly synthesized organo-antimony (v) ferrocenyl benzoate derivatives with piroxicam. Anti-microbial activity of these compounds was also screened against two microorganisms. Analgesic effect of test compounds was evaluated by formalin-induced paw licking test in mice. The test compounds at 50 and $100 \mathrm{mg} / \mathrm{kg}$ b.w. doses exhibited significant $(\mathrm{p}<0.001)$ reduction of paw licking in treated mice comparable with standard drug piroxicam. Anti-inflammatory activity was assessed against carrageenan-induced paw oedema. The compound A produced anti-inflammatory effects comparable with standard piroxicam in dose dependent manner whereas compound B showed better effects than piroxicam at dose of $100 \mathrm{mg} / \mathrm{kg}$ body weight. To investigate anti-pyretic activity, fever was induced by administration of Brewer's yeast in mice. Compound A showed highly significant inhibition of pyrexia $(\mathrm{p}<0.001)$ comparable to piroxicam after 3 hours while compound B (50 and $100 \mathrm{mg} / \mathrm{kg}$ ) produced relatively lower anti-pyretic effect than standard drug. Antibacterial activity determined by disc diffusion method showed that compound B was relatively more effective than compound A against Staphylococcus aureus and Klebsiella pneumoniae. It is conceivable that both the tested compounds possessed anti-inflammatory, analgesic, anti-pyretic and anti-microbial effects even after the structural modification of parent compound.
\end{abstract}

Key words: Analgesic, anti-inflammation, analgesic, anti-pyretic, piroxicam

\section{Introduction}

Pain has been defined as "an unpleasant sensory and emotional experience that is primarily associated with tissue damage and/or described in terms of such damage." It has been now broadly accepted that various types of mechanisms may involve in persistent pain and the different clinical manifestations have been used to divide pain syndromes into nociceptive, neuropathic, psychogenic, mixed, or idiopathic (Schaible, 2007). Nociceptive pain has been comprised acute or chronic inflammation. The inflammation has complex physiological nature. The neurogenic inflammation causes the release from nerve endings of compounds such as substance serotonin, histamine, acetylcholine and bradykinin. These substances stimulate and sensitize other nociceptors. Prostaglandins that are synthesized by injured tissues also may increase the nociceptive response to inflammation by reducing the threshold to noxious stimulation (Apkarian et al., 2005). Inflammation is a crucial aspect of host response that leads to infection and injury, and is obligatory to maintain healthy state against bacterial and viral infections. However, excessive or aberrant inflammation contributes to many acute and chronic human diseases (Serhan and Savill, 2005).

The pain and inflammation are often associated with pyrexia. A few degree body temperature elevation improves the efficiency of macrophages to kill the invading microorganisms, whereas it impairs bacterial replication, giving the immune system an adaptive advantage (Shylaja et al., 2008)

The first drugs used to treat inflammatory diseases were the non-steroidal anti-inflammatory drugs 
(NSAID). These agents reduce inflammation and help to relieve pain but seldom completely eradicate sign and symptoms of active arthritis (Matteson, 2000).

Despite newer developments made in drug discovery during the previous few decades, the treatment of many diseases especially inflammatory diseases is still a challenge. Modern anti-inflammatory drugs includes NSAID and other analgesic agents possesses various adverse effects like myocardial infarction (Kearney et al., 2006), congestive heart failure (Page and Henry, 2000), nausea, vomiting, dyspepsia, gastric ulceration, bleeding and diarrhea (Traversa et al., 1995) Therefore, studies on antiinflammatory drugs, and the development of newer and more powerful anti-inflammatory, analgesic and antipyretic drugs with fewer side effects are necessary. It is still needed to discover new drugs which are potent but safe with least side effects. So, it was considered worthwhile to evaluate anti-inflammatory, analgesic, anti-pyretic and antimicrobial activities of newly synthesized organo-antimony (v) ferrocenyl benzoate derivatives. The present study may ultimately help in discovering some novel ideal anti-inflammatory, analgesic, anti-pyretic and anti-microbial lead compounds for the effective treatment of different inflammatory and microbial diseases.

\section{Materials and Methods}

Synthetic test compounds:

Compound A: Bis (4-ferrocenyl benzoate) tris (p-tolyl) antimony (V)

Compound B: Bis (3- ferrocenyl benzoate) triphenylantimony $(\mathrm{V})$

These two synthetic test compounds were obtained from Department of Chemistry, Quaid-i- Azam University, Islamabad, Pakistan. The detailed synthesis and characterization of the test compounds have been previously reported (Asghar et al., 2012). Briefly, sodium salts of $m$-ferrocenyl benzoic acid $(0.01 \mathrm{~mol})$ or $p$-ferrocenyl benzoic acid ( $0.01 \mathrm{~mol})$ was added to 50 $\mathrm{ml}$ of chloroform in a double neck round bottom flask and the reaction mixture was allowed to stir for about an hour. Then $(0.005 \mathrm{~mol})$ organo-antimony (V) was added and the suspension was refluxed for 5-6 h. Precipitates of the salt formed were filtered off and the filtrate was evaporated under vacuum. Residue was dissolved in dichloromethane/chloroform and kept for crystallization. The structures of test compounds have been shown in the figure 1 and 2 .

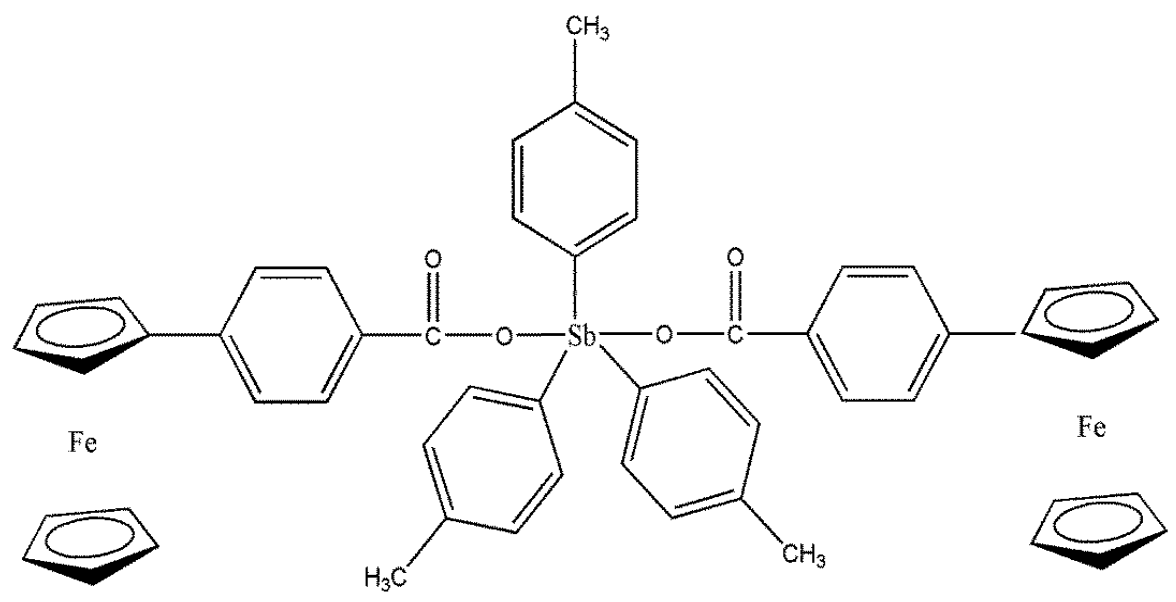

Figure 1. Bis (4-ferrocenyl benzoate) tris (p-tolyl) antimony (V). 


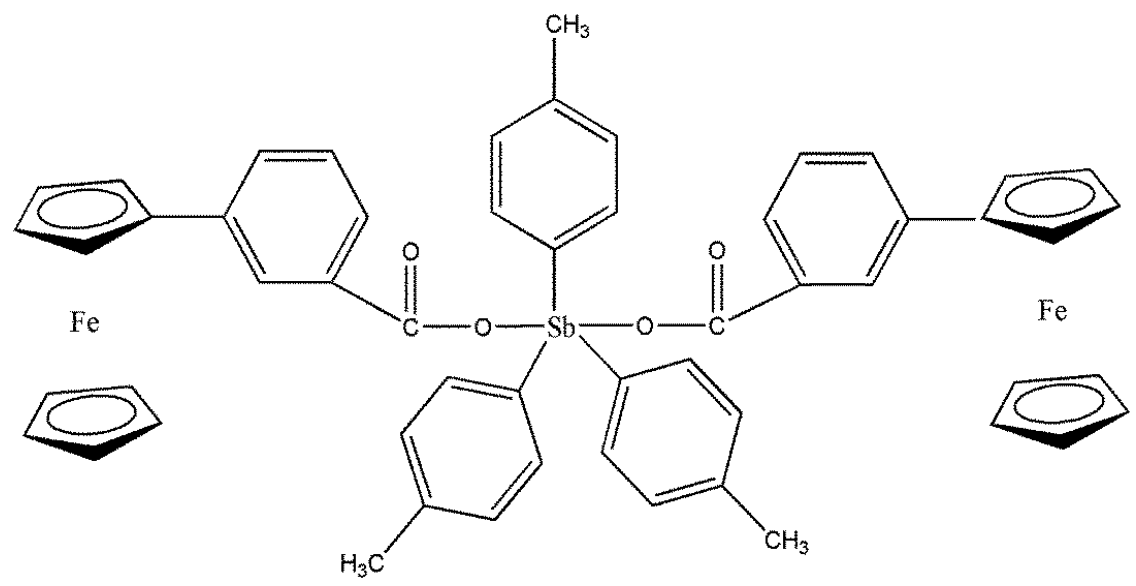

Figure 2. Bis (3- ferrocenyl benzoate) triphenylantimony (V).

Chemicals and culture media: Piroxicam (Hovid, Malaysia), Formalin (MERCK, Darmstadt, Germany), Carrageenan (Sigma Chemical Company. St. Louis, MO, USA), Dried yeast (Sigma Chemical Company. St. Louis, MO, USA), Nutrient broth (Merck, Germany), Mueller Hinton Agar medium (Merck, Germany), Normal saline $(0.9 \% \mathrm{NaCl})$.

Animals: Adult healthy male and female albino mice weighing 20-30 g were used. They were kept in stainless cages under controlled room temperature (25 \pm $10{ }^{\circ} \mathrm{C}$ ) relative humidity $60-70 \%$ ) and they were allowed free access to standard laboratory feed while water was provided ad libitum. Animals were handled according to the guidelines of NIH (National Institute of Health) are followed. The study protocols were approved by the local ethical committee of University of Sargodha, Sargodha.

Preparation of solutions/ suspensions of various drugs $1 \%(w / v)$ : Carrageenan suspension was prepared by taking $1 \mathrm{~g}$ of carrageenan in $100 \mathrm{ml}$ of normal saline. Formalin solution was prepared by dissolving $3.37 \mathrm{ml}$ of $37 \%$ formalin in $50 \mathrm{ml}$ of distilled water. Brewer's yeast suspension $[15 \%(\mathrm{w} / \mathrm{v})]$ was prepared by suspending $15 \mathrm{~g}$ of Brewer's yeast in $100 \mathrm{ml}$ of normal saline. Suspensions of both test compounds and piroxicam were prepared by dissolving them in water.

Drug administration: The solutions/ suspensions of drugs were administered to the animals by the following routes:
Oral administration: For oral administration of drugs oral gavage was used. Needle of $1 \mathrm{cc}$ B.D syringe was removed and Ryle tube \#4 attached to needle No. 17 was fixed at the place of original needle. Animal was maintained in upright position and the gavage was then passed from the side of mouth, following the mouth, and ensured that tube was entered to esophagus and stomach. Solution was directly injected in to the stomach by pressing plunger of syringe.

Subcutaneous administration: The skin of the animals between the shoulder blades was lifted up and a triangle was formed. The needle of the syringe was then introduced in the folds of the skin into the base of the triangle and drug was advanced into subcutaneous tissue. The drug was ejected by pressing the plunger of the syringe.

Analgesic activity: The analgesic effect of both test compounds was evaluated by method of Nwafor and Okwuasaba (2003) using formalin-induced paw licking test in mice. Mice (25-30 g) of either sex were randomized into 8 groups of 6 mice each. The animals were fasted for 24 hours and pretreated with different doses of compounds and piroxicam $5 \mathrm{mg} / \mathrm{kg}$ orally before being treated with formalin. $20 \mu \mathrm{l}$ of $2.5 \%$ formalin solution was injected subcutaneously to each mouse and the responses were observed for 30 minutes. The control animals were given $10 \mathrm{ml} / \mathrm{kg}$ distilled water orally. The amount of time (in second) spent in licking and biting the injected paw was measured and was indicative of pain. The first phase of the analgesic activity normally peaked at 5 minutes after formalin 
administration and the second phase 15-30 minutes after formalin injection.

Anti-inflammatory activity: Anti-inflammatory effects of both newly synthesized compounds were evaluated by carageenan-induced paw oedema in mice by following method used by Nasrin et al. (2015) with some modifications. Mice were divided into 8 groups of 6 mice each. The mice were kept at fasting for 24 hours before the start of experiment with free access to water only.

Group I served as control and received distilled water $10 \mathrm{ml} / \mathrm{kg}$ p.o. Group II was treated with the standard drug, piroxicam $5 \mathrm{mg} / \mathrm{kg}$ (Lee et al., 1999). Similarly three different doses $25 \mathrm{mg} / \mathrm{kg}, 50 \mathrm{mg} / \mathrm{kg}$ and $100 \mathrm{mg} / \mathrm{kg}$ of both test compounds dissolved in water were given orally to all other groups of animals by feeding tube. After $1 \mathrm{~h}$ of treatment the inflammation of the hind paw was produced by injecting $0.1 \mathrm{ml}$ freshly prepared carrageenan suspension (1\%) in normal saline (Latif et al., 2006) on the plantar surface of left hind paw of mice and site of injection was marked.

Anterio-posterior diameter of the paw was measured immediately after the carrageenan injection and at $0,1,2$ and 3 hours intervals by using digital vernier caliper. The difference between the basal value and that measured at different time intervals were noted in millimeters and this difference recorded as inflammation developed after carrageenan injection (Jude et al., 2008).

The left hind paw oedema inhibition at different doses of test drug and standard drug were calculated by comparing with untreated control mice by the following formula:

$\%$ inhibition of paw oedema $=$

$\frac{(\mathrm{Vt}-\mathrm{Vo})^{{ }^{\text {control }}-(\mathrm{Vt}-\mathrm{Vo})^{\text {treated }}}}{(\mathrm{Vt}-\mathrm{Vo})^{\text {control }}} \times 100$

Where $\mathrm{Vt}$ is the rat paw volume at time ' $\mathrm{t}$ ', $\mathrm{V}_{\mathrm{o}}$ is the initial rat paw volume (basal value), (Vt- Vo) ${ }^{\text {control }}$ is oedema produced in control group and (Vt- Vo) ${ }^{\text {treated }}$ is oedema produced in treatment group.

Anti-pyretic activity: Anti-pyretic activity against yeast- induced pyrexia in mice was performed according to the methods described by (Chitme et al., 2004).
The mice were divided into 8 groups of 6 mice each. The animals used in this study were kept on fasting for 24 hours before the beginning of experiment. Pyrexia was induced by subcutaneous administration of $10 \mathrm{mg} / \mathrm{kg}$ of aqueous suspension of Brewer's yeast (20\% in distilled water).

Group I (control group) was treated with normal saline $10 \mathrm{ml} / \mathrm{kg}$ p.o. Group II served as standard was treated with piroxican $5 \mathrm{mg} / \mathrm{kg}$ p.o. Group III, IV, V, VI, VII and VIII were treated with test compounds $\mathrm{A}$ and $\mathrm{B}$ respectively as $25 \mathrm{mg} / \mathrm{kg}$ p.o, $50 \mathrm{mg} / \mathrm{kg}$ p.o and $100 \mathrm{mg} / \mathrm{kg}$ p.o.

After 16 hours of induction of pyrexia, rectal temperatures were noted (pre-treatment values). The animals were treated as described earlier with control, standard and synthetic compounds. Rectal temperatures of animals were recorded at 1, 2, 3 and 4 hours after drug administration (Roy et al., 2012).

Anti-microbial study: Preparation of growth media: Nutrient broth was used to prepare the standard bacterial culture inoculum. Nutrient broth $(8 \mathrm{~g})$ was weighed on digital weighing balance (Sartorious GE4101, 0.1-4100 g), dissolved in distilled water (1000 $\mathrm{ml}$ ) and was sterilized in the autoclave for $15 \mathrm{~min}$ at $121{ }^{\circ} \mathrm{C}$.

Mueller Hinton Agar medium was used to screen the antibacterial activity of sample derivatives by disc diffusion method. M.H. Agar medium was prepared according to the manufacturer's guidelines (Merck, Germany). $34 \mathrm{~g}$ of M.H. Agar medium was weighed on digital weighing balance, dissolved in distilled water $(1000 \mathrm{ml})$ and was sterilized in the autoclave for $15 \mathrm{~min}$ at $121{ }^{\circ} \mathrm{C}$. Then the M.H. Agar medium was poured into sterile plastic petri plates (diameter- $84 \mathrm{~mm}$ ) under the safety cabinet. Plates were then left under the safety cabinet to solidify.

Sub-culturing of test micro organism: Nutrient broth was used to prepare the standard culture inoculum of $S$. aureus and $K$. pneumoniae. Nutrient broth $(2 \mathrm{ml})$ was taken in a sterile screw capped test tube and was inoculated with a single isolated colony of test strain using a sterile wire loop. Culture inoculum was incubated (Incubator Model B-53 GmbH) at $37{ }^{\circ} \mathrm{C}$ until the turbidity of inoculum became equivalent to that of 0.5 MacFarland standard. 
Disc diffusion method: Antibacterial activity of test compounds was determined by disc diffusion method with a few modifications. $10 \mu \mathrm{g}$ of both derivatives was dissolved in $10 \mu \mathrm{l}$ of DMSO. The samples were applied on sterile Whatman No.1 filter paper discs (6 $\mathrm{mm}$ diameter) and dried under sterile conditions. Sterile M.H agar plates were used to-screen antibacterial activity of samples which were inoculated with freshly prepared overnight culture of Klebsiella pneumoniae and Staphylococcus aureus by preparing the lawn on the sterile agar-using a sterile cotton swab. After 15 minutes of preparing the microbial lawn, samples discs were applied on the inoculated M.H. Agar surface with the help of sterile forceps. Petri plates were covered, labeled and placed in the incubator (Model B-53 $\mathrm{GmbH})$ at $37{ }^{\circ} \mathrm{C}$ for 24 hours. Antibacterial activity of both samples was determined by measuring the diameter of zone of inhibition next day using a Vernier caliper. Chloramphenicol $(30 \mu \mathrm{g})$ was used as positive control and respective DMSO discs were used as negative control. Experiment was performed in triplicate (Hossain et al., 2014).

Statistical analysis: The results are expressed as means \pm SEM. Parametric data was compared to control group and were assessed by the method of oneway ANOVA followed by Dunnet's test and two-way ANNOVA followed by Bonferroni posts-test. Values $\mathrm{p}<0.05$ were considered as statistically significant.

\section{Results}

The amount of time (in second) spent in licking was recorded in all 8 groups to determine the analgesic activity. The mean time of licking for control group was calculated as 2.83 minutes. The analgesic activities of all groups were calculated by comparing the mean percentage inhibition of time of licking with control. The effect of both the test compounds and piroxicam against formalin induced paw licking time in mice are shown in table 1 . The mean percentage inhibition of time spent in licking of group 2 treated with standard drug piroxicam was calculated to be $59.8 \%$ and showed highly significant inhibition of paw licking $(\mathrm{p}<0.001)$. Mean percentage inhibition of time spent in licking of groups 3, 4 and 5 treated with compound A 25, 50 and $100 \mathrm{mg} / \mathrm{kg}$ body weigh were calculated to be $36 \%$,
$46.9 \%$, and $51.2 \%$, respectively. Results showed that compound A produced analgesic effects in a dose dependent manner. In $25 \mathrm{mg} / \mathrm{kg}$ dose compound A produces non-significant analgesic effect while in higher doses 50 and $100 \mathrm{mg} / \mathrm{kg}$ produced highly significant and comparable analgesic effect with standard drug piroxicam. Mean $\%$ inhibition of time spent in licking of groups 6,7 and 8 treated with compound B 25, 50 and $100 \mathrm{mg} / \mathrm{kg}$ body weigh were calculated to be $35 \%, 48 \%$, and $52.6 \%$, respectively. Compound $\mathrm{B}$ also produces analgesic effect in a same pattern as compound A i.e. in $25 \mathrm{mg} / \mathrm{kg}$ dose it produces non-significant $\mathrm{p}>0.05$ effect while in higher doses $50 \mathrm{mg} / \mathrm{kg}$ and $100 \mathrm{mg} / \mathrm{kg}$ compound $\mathrm{B}$ also produces highly significant $\mathrm{p}>0.001$ which was comparable to analgesic effect of the standard drug, piroxicam $(5 \mathrm{mg} / \mathrm{kg}$, p.o.)

Anti-inflammatory activity: To determine the antiinflammatory activity of various drugs, effect in all 8 groups of mice was determined. The effects of both the test compounds on carrageenan-induced oedema in mice are shown in table 2 and 3. The both test compounds showed comparable anti-inflammatory effects with standard piroxicam after three hours of induction of inflammation in mice. The compound A has produced comparable anti-inflammatory effects with standard piroxicam in a dose dependent manner. The compound B have shown comparable antiinflammatory effects with standard piroxicam at a dose of $50 \mathrm{mg} / \mathrm{kg}$ body weight, but shows better effects at dose of $100 \mathrm{mg} / \mathrm{kg}$ body weight. Both test compounds showed prominent anti-inflammatory effects in a dose dependent manner. Compound A showed nonsignificant anti-inflammatory effect in $25 \mathrm{mg} / \mathrm{kg}$ dose even after 3 hours of induction of inflammation but in $50 \mathrm{mg} / \mathrm{kg}$ and $100 \mathrm{mg} / \mathrm{kg}$ doses compound A have shown therapeutically significant $(p>0.001)$ antiinflammatory effects comparable with standard drug piroxicam. Similarly compound B have also shown dose dependent pattern i.e in lower dose $25 \mathrm{mg} / \mathrm{kg}$ shown non-significant anti-inflammatory effect but in higher doses $50 \mathrm{mg} / \mathrm{kg}$ and $100 \mathrm{mg} / \mathrm{kg}$ doses compound $B$ have showed therapeutically significant $(p>0.001)$ anti-inflammatory effects comparable with standard drug piroxicam. 
Anti-pyretic activity: To determine the anti-pyretic activity of test compounds induced by yeast the mean temperature before and after yeast dose was recorded in all 8 groups. The mean temperatures of control group after one, two and three hours were $38.30{ }^{\circ} \mathrm{C}, 38.05{ }^{\circ} \mathrm{C}$ and $38{ }^{\circ} \mathrm{C}$ respectively as shown in table 4 . The mean temperature of group two treated with standard drug piroxicam after 1,2 and 3 hours were $38.15{ }^{\circ} \mathrm{C}, 37.5$ and $35.87{ }^{\circ} \mathrm{C}$, respectively. Compound $\mathrm{A}$ at doses 50 $\mathrm{mg} / \mathrm{kg}$ and $100 \mathrm{mg} / \mathrm{kg}$ showed highly significant inhibition of pyrexia $(\mathrm{p}<0.001)$ while compound B not showed significant anti-pyretic activity compared with piroxicam. Results indicate that compound A produced non-significant anti-pyretic effects in $25 \mathrm{mg} / \mathrm{kg}$ dose but in doses $50 \mathrm{mg} / \mathrm{kg}$ and $100 \mathrm{mg} / \mathrm{kg}$ produced significant $(p>0.001)$ and potent anti-pyretic effects comparable with standard drug piroxicam. Compound B produces non-significant anti-pyretic effects in all doses $25 \mathrm{mg} / \mathrm{kg}, 50 \mathrm{mg} / \mathrm{kg}$ and $100 \mathrm{mg} / \mathrm{kg}$ body weight.

Table 1. Effect of synthetic test compounds against formalin induced paw licking time in mice.

\begin{tabular}{ccc}
\hline Treatment/Dose & Licking time (minutes) & \% Inhibition \\
\hline Control 10m1/kg (Saline) P.O & $2.83 \pm 0.26$ & \\
Piroxicam 5 mg/kg P.O & $1.135 \pm 0.01^{* * *}$ & $60 \%$ \\
Compound A 25 mg/kg P.O & $2.73 \pm 0.26^{\mathrm{ns}}$ & $36 \%$ \\
Compound A 50mg/kg P.O & $1.50 \pm 0.03^{* * *}$ & $46.9 \%$ \\
Compound A 100mg/kg P.O & $1.38 \pm 0.04^{* * *}$ & $51.2 \%$ \\
Compound B 25 mg/kg P.O & $2.68 \pm 1.20^{\mathrm{ns}}$ & $35 \%$ \\
Compound B 50mg/kg P.O & $1.47 \pm 0.02^{* * *}$ & $48 \%$ \\
Compound B 100mg/kg P.O & $1.34 \pm 0.002^{* * *}$ & $52.6 \%$ \\
\hline
\end{tabular}

Data is expressed as means \pm SEM using two ways ANOVA.

Significant at $* * *=\mathrm{p}<0.001$, and $\mathrm{ns}=$ Non-significant, when compared with control.

Table 2. Anti-inflammatory effects of synthetic test compounds in carrageenan-induced paw oedema in albino mice.

\begin{tabular}{|c|c|c|c|c|}
\hline Treatement/ Dose & Inflammation at $0 \mathrm{~h}$ & Inflammation at $1 \mathrm{~h}$ & Inflammation at $2 \mathrm{~h}$ & Inflammation at $3 \mathrm{~h}$ \\
\hline Control & $4.35 \pm 0.05$ & $4.40 \pm 0.10$ & $4.8 \pm 0.10$ & $5.22 \pm 0.07$ \\
\hline $\begin{array}{l}\text { Piroxicam }(5 \mathrm{mg} / \mathrm{kg}) \\
\text { P.O }\end{array}$ & $3.30 \pm 0.09 *$ & $3.05 \pm 0.06^{*}$ & $2.90 \pm 0.05^{*}$ & $2.8 \pm 0.06^{*}$ \\
\hline $\begin{array}{l}\text { Compound A ( } 25 \mathrm{mg}) \\
\text { P.O }\end{array}$ & $4.30 \pm 0.07$ & $4.40 \pm 0.10^{\mathrm{ns}}$ & $4.80 \pm 0.10^{\mathrm{ns}}$ & $23 \pm 0.04^{\mathrm{ns}}$ \\
\hline $\begin{array}{l}\text { Compound A (50mg) } \\
\text { P.O }\end{array}$ & $3.37 \pm 0.06$ & $3.20 \pm 0.04 *$ & $3.10 \pm 0.05^{*}$ & $3.05 \pm 0.025^{*}$ \\
\hline $\begin{array}{l}\text { Compound A (100mg) } \\
\text { P.O }\end{array}$ & $4.00 \pm 0.08$ & $3.07 \pm 0.06^{*}$ & $2.97 \pm 0.06^{*}$ & $2.82 \pm 0.08^{*}$ \\
\hline $\begin{array}{l}\text { Compound B ( } 25 \mathrm{mg}) \\
\text { P.O }\end{array}$ & $4.37 \pm 0.06^{\mathrm{ns}}$ & $4.20 \pm 0.04^{\mathrm{ns}}$ & $4.10 \pm 0.05^{\mathrm{ns}}$ & $4.20 \pm 0.02^{\mathrm{ns}}$ \\
\hline $\begin{array}{l}\text { Compound B }(50 \mathrm{mg}) \\
\text { P.O }\end{array}$ & $3.17 \pm 0.08$ & $3.02 \pm 0.08^{*}$ & $2.95 \pm 0.08^{*}$ & $2.92 \pm 0.07 *$ \\
\hline $\begin{array}{l}\text { Compound B (100mg) } \\
\text { P.O }\end{array}$ & $3.17 \pm 0.08$ & $3.05 \pm 0.05^{*}$ & $2.90 \pm 0.04 *$ & $2.75 \pm 0.09 *$ \\
\hline
\end{tabular}

Data are expressed as means \pm SEM using two way ANOVA. Significant at $* * *=p<0.001, \quad * *=p<0.01$ and $*=p<0.05$ when compared with control 
Table 3. \% age Inhibition of carrageenan-induced paw oedema in mice at $1 \mathrm{~h}, 2 \mathrm{~h}$ and $3 \mathrm{~h}$.

\begin{tabular}{cccc}
\hline Treatement/ Dose & \%age Inhibition at $1 \mathrm{~h}$ & \%age Inhibition at $2 \mathrm{~h}$ & \%age Inhibition at $3 \mathrm{~h}$ \\
\hline Piroxicam (5 mg/kg) P.O & $31 \%$ & $40 \%$ & $46 \%$ \\
Compound A (25 mg) P.O & $11 \%$ & $4 \%$ & $18 \%$ \\
Compound A( 50mg) P.O & $27 \%$ & $35 \%$ & $43 \%$ \\
Compound A (100mg) P.O & $30 \%$ & $38 \%$ & $46 \%$ \\
Compound B (25 mg) P.O & $5 \%$ & $14 \%$ & $19 \%$ \\
Compound B (50mg) P.O & $31 \%$ & $39 \%$ & $44 \%$ \\
Compound B (100mg) P.O & $31 \%$ & $40 \%$ & $47 \%$ \\
\hline
\end{tabular}

Table 4. Antipyretic effects of test compounds against yeast induced pyrexia in mice.

\begin{tabular}{|c|c|c|c|c|c|}
\hline \multirow[t]{2}{*}{ Treatment/Dose } & \multicolumn{5}{|c|}{ Temperature ${ }^{\circ} \mathrm{C}$} \\
\hline & before induction & $\begin{array}{l}\text { after } 24 \mathrm{~h} \text { of } \\
\text { induction }\end{array}$ & $\begin{array}{l}\text { after } 1 \mathrm{~h} \text { of } \\
\text { treatment }\end{array}$ & $\begin{array}{l}\text { after } 2 \mathrm{~h} \text { of } \\
\text { treatment }\end{array}$ & after $3 \mathrm{~h}$ of treatment \\
\hline Control 10ml/kg (P.O) & $36.40 \pm 0.56$ & $38.30 \pm 0.23$ & $38.30 \pm 0.23$ & $38.05 \pm 0.02$ & $38.0 \pm 0.00$ \\
\hline Piroxicam 5mg/kg (P.O) & $36.87 \pm 0.05^{\mathrm{NS}}$ & $39.1 \pm 0.08^{\mathrm{NS}}$ & $38.15 \pm 0.1^{\mathrm{NS}}$ & $37.52 \pm 0.2^{\mathrm{NS}}$ & $35.87 \pm 0.3 * * *$ \\
\hline $\begin{array}{l}\text { Compound A } 25 \mathrm{mg} / \mathrm{kg} \\
\text { (P.O) }\end{array}$ & $37.40 \pm 0.56^{\mathrm{NS}}$ & $36.30 \pm 0.23^{\mathrm{NS}}$ & $39.30 \pm 05^{\mathrm{NS}}$ & $39.0 \pm 0.02^{\mathrm{NS}}$ & $37.01 \pm 0.1^{\mathrm{NS}}$ \\
\hline $\begin{array}{l}\text { Compound A } 50 \mathrm{mg} / \mathrm{kg} \\
\text { (P.O) }\end{array}$ & $36.9 \pm 0.06^{\mathrm{NS}}$ & $39.1 \pm 0.06^{\mathrm{NS}}$ & $38.42 \pm 0.2^{\mathrm{NS}}$ & $37.80 \pm 0.2^{\mathrm{NS}}$ & $36.57 \pm 0.2 * * *$ \\
\hline $\begin{array}{l}\text { Compound A } \\
100 \mathrm{mg} / \mathrm{kg}(\mathrm{P} . \mathrm{O})\end{array}$ & $36.72 \pm 0.2^{\mathrm{NS}}$ & $38,80 \pm 0.2^{\mathrm{NS}}$ & $37.1 \pm 0.02^{\mathrm{NS}}$ & $37.35 \pm 0.1^{\mathrm{NS}}$ & $36.47 \pm 0.4^{* * *}$ \\
\hline $\begin{array}{l}\text { Compound B 25mg/kg } \\
\text { (P.O) }\end{array}$ & $38.30 \pm 0.23^{\mathrm{NS}}$ & $36.05 \pm 0.02^{\mathrm{NS}}$ & $\begin{array}{l}38.01 \pm \\
0.10^{\mathrm{NS}}\end{array}$ & $38.0 \pm 0.03^{\mathrm{NS}}$ & $37.01 \pm 0.01$ \\
\hline $\begin{array}{l}\text { Compound B 50mg/kg } \\
\text { (P.O) }\end{array}$ & $36.97 \pm 0.2^{\mathrm{NS}}$ & $38.55 \pm 0.2^{\mathrm{NS}}$ & $38.10 \pm 0.3^{\mathrm{NS}}$ & $37.55 \pm 0.2^{\mathrm{NS}}$ & $37.10 \pm 0.1 *$ \\
\hline $\begin{array}{l}\text { Compound B } 100 \mathrm{mg} / \mathrm{kg} \\
\text { (P.O) }\end{array}$ & $37.10 \pm 0.1^{\mathrm{NS}}$ & $38.9 \pm 0.08^{\mathrm{NS}}$ & $38.17 \pm 0.2^{\mathrm{NS}}$ & $37.42 \pm 0.1^{\mathrm{NS}}$ & $36.95 \pm 0.1^{*}$ \\
\hline
\end{tabular}

Data are expressed as means \pm SEM using two ways ANOVA.

Significant at $* * *=p<0.001, *=p<0.05$ when compared with control.

Antibacterial activity: After 24 hours of incubation agar plates were checked for zones of inhibition. The results of antibacterial activity of both the tested compounds are shown in table 5. Compound A produced $10 \pm 0.24 \mathrm{~mm} \quad 09 \pm 0.23 \mathrm{~mm}$ zones of inhibition against $K$. pneumoniae and $S$. aureus respectively. Significantly compound B produced 11 $\pm 0.20 \mathrm{~mm}$ zone of inhibition against both $K$. pneumoniae and $S$. aureus.

Antibacterial activity was determined by disc diffusion method, measuring the zone of inhibition. Study showed that Compound A was more effective against $K$. pneumoniae compared to $S$. aureus. It shows
Table 5. Antimicrobial activity of test compound against S. aureus and $K$. pneumonia.

Test Compounds zone of inhibition in $\mathrm{mm} \pm$ Standard deviation $(\mathrm{n}=5)$

\begin{tabular}{lcc}
\hline against $S$. aureus & \multicolumn{2}{c}{ against K. pneumoniae } \\
\hline Compound A & $09 \pm 0.23$ & $10 \pm 0.24$ \\
Compound B & $11 \pm 0.20$ & $11 \pm 0.20$ \\
\hline
\end{tabular}

that Compound A may be therapeutically effective against $S$. aureus. There is need for further study by using different concentrations of Compound A against $K$. pneumoniae to determine its most effective concentration and also its MIC (Minimum inhibitory concentration) and MBC (Minimum bacterialcidal concentration) values. Compound B was more effective 
than Compound A against both $S$. aureus and strains. At these concentrations $11 \mathrm{~mm}$ zone of inhibition may be therapeutically valuable result so there is need for further study. There is need to determine their mechanism of action. If these compounds show any synergism or addition in the activities of conventional antibiotics then it will be a good achievement and will be a great contribution to the treatment of many infectious diseases.

\section{Discussion}

Anti-inflammatory, analgesic and antipyretic activities have similar basic mechanism, but compounds vary in their profile of activity. Currently available drugs for pain and inflammation mainly include paracetamol and other NSAIDs, COX2 inhibitors, opiates and other agents like anticonvulsants are used to treat neuropathic pain with modest achievement. Non-steroidal antiinflammatory drugs (NSAIDs) relieve pain by counteracting the cyclooxygenase (COX) enzyme and therefore prostaglandin synthesis. These also have antipyretic activity, since prostaglandins are implicated in the mediation of fever (Reddy et al., 2000). Modern NSAIDs produce serious side effects. The gastric ulcer, kidney and liver dysfunction, arterial hypertension and type 2 diabetes mellitus are most frequently associated with use of NSAIDs. Therefore, it is still needed to discover new drugs which are potent but safe with least side effects.

The test compounds Bis (4-ferrocenyl benzoate) tri (p-tolyl) antimony (v) and Bis (3-ferrocenyl benzoate) triphenylantimony (v) showed anti-inflammatory and analgesic effects.

Results obtained after experimental work in the study indicate that both synthetic test compounds at 50 and $100 \mathrm{mg}$ doses exhibit analgesic activity $(\mathrm{P}<0.0001)$ by reducing the time for licking in formalin injected paw in mice.

Formalin has been reported to exhibit neurogenic and inflammatory pain (Vaz et al., 1996). The potential effect of test compounds observed on the first and second phase of formalin-induced paw licking test have suggested that this effect may be because of its central action (Ghannadi et al., 2005).
Analgesics such as opioids have been shown to inhibit both phases of pain induced by formalin by acting on central nervous system while aspirin, hydrocortisone and dexamethasone act peripherally, thereby inhibiting only the second phase of pain (Shibata et al., 1989). Assessment of the antinociceptive response using the formalin test showed that all the doses (25, 50 and $100 \mathrm{mg})$, inhibited both phases of pain. The highest dose (100 mg) exhibited more prominent response to the pain at both phases compared to piroxicam.

The anti-inflammatory activity of synthetic test compounds has been observed by using carrageenaninduced oedema in mice. The carrageenan-induced paw oedema model in mice is an acute inflammatory model been used to estimate the effect of NSAIDs which primarily inhibit prostaglandin (PG) synthesis by counteracting the cyclo-oxygenase enzymes. The development of oedema by carrageenan in mice is comprised of two phases. In the first phase, between 0 to $2.5 \mathrm{~h}$ of injecting carrageenan, the release of serotonin and/or histamine occurs whereas in the second phase prostaglandins, bradykinin and protease are released and it reaches to maximum after about $3 \mathrm{~h}$ of post inflammagen administration (Moulisha et al., 2011). Therefore, the inhibitory effect on the carrageenaninduced inflammation produced by effective synthetic compounds including $\mathrm{A}$ and $\mathrm{B}$ may be due to the prostaglandin synthesis inhibition.

To evaluate anti-pyretic activity of test compounds, pyrexia was induced by yeast. All the synthetic compounds have anti-pyretic activity. The results showed that synthetic compound such as compound A and $\mathrm{B}$ at the dose of $50 \mathrm{mg}$ and $100 \mathrm{mg}$ significantly $(\mathrm{P}<0.0001)$ inhibited pyrexia. It has been recognized that yeast induces-pyrexia by increasing the production of prostaglandins, mainly $\mathrm{PGE}_{2}$, which raises the set point of the thermoregulatory center in hypothalamus (Rititid et al., 2007).

Appearance of multidrug resistance in bacteria, causing infectious diseases has created enormous clinical problems in the management of these infectious diseases. Scientists are now in search of alternative medicines from natural sources like plants and animals. Antibacterial activity was determined by disc diffusion 
method, measuring the zone of inhibition. Study showed that Compound A was more effective against $K$. pneumoniae compared to $S$. aureus. It shows that compound A may be therapeutically effective against $K$. pneumoniae. There is need for further study by using different concentrations of Compound A against $K$. pneumoniae to determine its most effective concentration and also its MIC and MBC values. Compound $\mathrm{B}$ is more effective than compound $\mathrm{A}$ against both $S$. aureus and $K$. pneumoniae strains. At this concentration $11 \mathrm{~mm}$ zone of inhibition may be therapeutically valuable result so there is need for further study. There is need to determine their mechanism of action. If these derivatives show any synergism or addition in the activities of conventional antibiotics then it will be a good achievement and will be a great contribution to the treatment of many infectious diseases.

It is concluded that both the tested compounds possess anti-inflammatory, analgesic, anti-pyretic and anti-microbial effects even after the structural modification of the parent compound. However, further studies would be essentially required to elucidate the exact mechanism of anti-inflammatory, analgesic, antipyretic and anti-microbial activities of the compounds tested to establish safety and efficacy in human patients according to the approved FDA protocols.

\section{Acknowledgement}

The authors are grateful to Prof. Dr. Amin Badshah, Chairperson, Department of Chemistry, Quaid-i- Azam University, Islamabad, Pakistan for generously providing the synthetic compounds for the present study.

\section{References}

Apkarian, A.V., Bushnell, M.C., Treede, R.D. and Zubieta, J.K. 2005. Human brain mechanisms of pain perception and regulation in health and disease. Eur. J. Pain. 9, 463484.

Asghar, F., Badshah, A., Shah, A., Rauf, M.A., Ali, M.I., Tahir, M.N., Nosheen, E., Rehman, Z.U. and Qureshi, R. 2012. Synthesis, characterization and DNA binding studies of organoantimony (V) ferrocenyl benzoates. $J$. Organomet. Chem. 717, 1-8.
Ghannadi, A., Hajhashemi, V. and Jafarabadi, H. 2005. An investigation of the analgesic and anti-inflammatory effects of Nigella sativa seed polyphenols. J. Med. Food. 8, 488-493.

Hossain, M.D.B., Salam, M.D.A., Rashed, A. and Yousuf, M.A. 2014. Synthesis, Characterization and Antibacterial Studies of the Mixed Ligand Complexes of Pd (II) and Pt (II) Ions with Phthalic Acid and Heterocyclic Amines. Bangladesh Pharm. J. 17, 157-162.

Jude, E.O., Bassey, S.A. and Emem, U. 2008. Analgesic and anti-inflammatory effects of ethanolic extracts of Hippocratia africana. Int. J. Pharmacol. 4, 51-55.

Karthikeyan, M. and Deepa, M.K. 2011. Anti-inflammatory activity of Premna corymbosa (Burm. f.) Rottl. \& Willd. leaves extracts in Wistar albino rats. Asian Pac. J. Trop. Med. 4, 510-513.

Kearney, Pm., Baigent, C., Godwin, J., Halls, H., Emberson, J.R. and Patrono, C. 2006. Do selectivecyclo-xygenase-2 inhibitors and traditional nonsteroidal anti-inflammatory drugs increase the risk of atherothrombosis. Metaanalysis of randomised trials. British Med. J. 332, 13021308.

Latif, A., Khan, T.F. and Afaq, S.H. 2006. Anti-inflammatory activity of Flower tops of Gentiana kurroo Royale extract. Pharmacologyonline. 3, 575-580.

Lee, E.B., Kwon, S.K. and Kim, S.G. 1999. Synthesis and analgesic and anti-inflammatory activities of 1, 2Benzothiazine derivatives. Arch. Pharm. Res. 22, 4447.

Matteson, E.L. 2000. Current treatment strategies for rheumatoid arthritis. Mayo Clin. Proc. 75, 69-74.

Moulisha, B., Kaushik, B., Tarun, K.K., Bhattacharya, S., Ashoke, K.G. and Pallab, K.H. 2011. Evaluation of analgesic and anti- inflammatory activities of Terminalia arjuna Leaf. J. Phytol. 3, 33-38.

Nasrin, F., Bulbul, I.J., Aktar, F. and Rashid, M.A. 2015. Anti-inflammatory and antioxidant activities of cucumis sativus leaves. Bangladesh Pharm. J. 18, 169-173.

Page, J. and Henry, D. 2000. Consumption of NSAIDs and the development of congestive heart failure in elderly patients: an underrecognized public health problem. Arch. Int. Med. 160, 777-784. 
Reddy, B.S., and Rao, C.V. 2002. Novel approaches for colon cancer prevention by cyclooxygenase- 2 inhibitors. $J$. Environ. Pathol. Toxicol. Oncol. 21, 155-164.

Rititid, W., Ruangsang, P., Reanmongkol, W., Wongnawa, M. 2007. Studies of the anti-inflammatory and anti-pyretic activities of the methanolic extract of Piper sarmentosum Roxb. leaves in rats. Songklanakarin J. Sci. Tech. 29, 1519-1526.

Roy, D., Shill, M.C., Dev, S., Deb, D., Shahriar, M., Das, A.K. and Choudhuri, M.S.K. 2012. Anti-nociceptive and antipyretic activities of hydroalcoholic extract of cassia sophera Linn. leaves. Bangladesh Pharm. J. 15, 107-111.

Schaible, H.G. 2007. Peripheral and central mechanisms of pain generation. Handb. Exp. Pharmacol. 177, 3-28.

Serhan, C.N. and Savill, J. 2005. Resolution of inflammation: The beginning programs the end. Nat. Immunol. 6, 1191-1197.
Shibata, M., Ohkubo, T., Takahashi, H. and Inoki, R. 1989. Modified formalin test: Characteristic biphasic pain response. Pain. 38, 347-352.

Shylaja, H., Lakshman, K., kar, N., Maurya, V., and Viswantha, G.L. 2008. Analgesic and anti-inflammatory activity of topical preparation of Lantan camara L leaves. Pharmacologyonline 1, 90-96.

Traversa, G., Walker, A.M., Ippolito, F.M., Caffari, B., Capurso, L., Dezi, A., Koch, M., Maggini, M., Alegiani, S.S. and Raschetti, R. 1995. Gastroduodenal toxicity of different non-steroidal anti-inflammatory drugs. Epidemiol. 6, 49-54.

Vaz, Z.R., Filho, V.C., Yunes, R.A. and Calixto, J.B. 1996. Antinociceptive action of 2-(4 bromobenzoyl) 3-methyl4-6-dimethoxy bezofuran, a novel xanthoxyline derivative of chemical and thermal models of nociception in mice. J. Pharmacol. Exp. Ther. 278, 304312. 